\title{
IN VIVO CHARACTERIZATION OF LESS PAINFUL PROPOFOL NANOEMULSION USING PALM OIL FOR INTRAVENOUS DRUG DELIVERY
}

\author{
BAYU EKO PRASETYO ${ }^{1,2}$, NORAZRINA AZMI ${ }^{3}$, AHMAD FUAD SHAMSUDDIN ${ }^{*}$
}

1Department of Pharmaceutical Technology, Faculty of Pharmacy, Universitas Sumatera Utara, Medan, 20155, Indonesia, ${ }^{2}$ Nanomedicine Center of Innovation, Universitas Sumatera Utara, Medan, 20155, Indonesia. ${ }^{3}$ Faculty of Pharmacy, Universiti Kebangsaan Malaysia, Jalan Raja Muda Abdul Aziz, 50300 Kuala Lumpur, Malaysia, ${ }^{4}$ Faculty of Pharmacy and Health Sciences University Kuala Lumpur Royal College of Medicine Perak (UniKL RCMP) No. 3 Jalan Greentown 30450 Ipoh, Perak

Email: drafsna@gmail.com

Received: 13 Mar 2019, Revised and Accepted: 26 Apr 2019

\section{ABSTRACT}

Objective: The objective of present work was to evaluate the effectiveness of propofol in nanoemulsion-based palm oil that called as NEMS ${ }^{\mathrm{Tm}}$, which was a choice of anesthetic drug to induce and maintenance general anesthesia to reduce pain on injection activity and also to evaluate the in vivo characterization of propofol in $\mathrm{NEMS}^{\mathrm{TM}}$.

Methods: Preparation of propofol nanoemulsion using NEMS ${ }^{\mathrm{TM}}$ technology has been performed for propofol $1 \%$ in NEMS ${ }^{\mathrm{TM}}$ (P1\%), and propofol 2\% in NEMS ${ }^{\mathrm{TM}}$ (P2\%). Determination of free propofol concentration in the aqueous phase was conducted using HPLC and rat paw lick test was evaluated as in vivo test to assay the intensity of pain on injection site. The sleep recovery test was conducted to evaluate the pharmacological effect and erythrocyte hemolysis test also conducted to ensure the safety of propofol in NEMS ${ }^{\mathrm{M}}$. All of the test results were compared with Diprivan ${ }^{\circledR} \%$ as a positive standard.

Results: The contents of free propofol in formulation P1\% and Diprivan ${ }^{\circledR} 1 \%$ in aqueous-phase were $6.20 \pm 0.03 \mu \mathrm{g} / \mathrm{ml}$ and $15.02 \pm 0.33 \mu \mathrm{g} / \mathrm{ml}$, respectively $\left({ }^{*} \mathrm{P}<0.05\right)$. The rat paw lick test showed that the formulation $\mathrm{P} 1 \%$ was significantly $\left({ }^{*} \mathrm{P}<0.05\right)$ less painful when compared to Diprivan ${ }^{\circledR} 1 \%$. There were no significant differences in pharmacological effect for all of the formulations $\left({ }^{*} \mathrm{P}>0.05\right)$. The erythrocyte haemolysis test shows that all formulation was still safe for our blood.

Conclusion: Palm oil can be used as a carrier for propofol and it was successfully reduced the free propofol contents and the intensity of pain on injection site in rats.

Keywords: Palm oil, NEMS ${ }^{\mathrm{TM}}$, Propofol, MCT/lCT, Nanoemulsion

(C) 2019 The Authors. Published by Innovare Academic Sciences Pvt Ltd. This is an open access article under the CC BY license (http://creativecommons.org/licenses/by/4.0/) DOI: http://dx.doi.org/10.22159/ijap.2019v11i4.33039

\section{INTRODUCTION}

Propofol nanoemulsion using soya as the oil phase has been used for decades in clinical application. This drug is widely used in surgery procedure and also generally used in an intensive care unit all around the world. Perhaps, this is the reason why it becomes one of the popular anesthetic agents [1]. So far, this dosage form is reputed success because it has a rapid onset of action, short duration of action and minimum side effects [2].

Unfortunately, it was found so many disadvantages from this dosage form. Pain of injection is one of the serious problems that often happen to the patients [3-5]. Many researchers have tried to find the solution how to reduce the pain such as by using rapid injection technic [6], utilizing the analgesic drug before injection, such as lidocain [7], ephedrine [8], saline dilution [9], paracetamol [10], lornoxicam [11], etc. However, the best solution to treat the pain has not been discovered [4]. Further studies are needed to make an effective formulation.

The clear mechanism why there is pain on site following injection is still not well understood. Some researchers make an assumption that the free propofol in the aqueous phase of propofol nanoemulsion is known to be related with the intensity of pain at the injection time [12]. The utilization of propofol nanoemulsion using a mixture of medium chain triglyceride (MCT)/long-chain triglyceride (LCT) to reduce the intensity of pain has become one of the safety solutions to be used [3,13-15]. Yamakage et al. [14] stated that MCT/ICT propofol nanoemulsion reduces the concentration of free propofol until $30-35 \%$ so that it will reduce the pain.

In this study, palm olein oil (POO) as the source of palm oil was used instead of soya oil as an oil phase in propofol nanoemulsion preparation. This oil is easily to find and commonly people use it as cooking oil, in margarine preparation and as an additive for food preparation [16, 17]. However, the application of this oil in pharmaceutical was still uncommon although this oil has the potentiality to be developed. Production of this oil every year is very high. This oil came originally from West Africa and it was introduced to Brazil and other topical countries in $15^{\text {th }}$ century. Currently, Malaysia and Indonesia are two countries with the highest production of palm oil in the world [18].

In the present study, the comparison in intensity of pain from $\mathrm{P} 1 \%$ and P2\% with Diprivan $\AA 1 \%$ was evaluated by determination of free propofol concentration in the aqueous phase by HPLC method. The rat paw lick test was performed to compare the intensity of pain in animals after injection. The sleep recovery test was conducted to compare the pharmacological effect of the formulations to Diprivan $\AA$.

\section{MATERIALS AND METHODS}

\section{Materials}

The following materials were obtained from the sources in brackets. Pure Propofol and Lipoid E-80 (GmbH, Ludwigshaffen, Germany), Malaysian local palm oil for source of palm olein oil (POO) and MCT oil (Enersos, PharmaD Sdn. Bhd, Malaysia), Glycerol (Sigma Aldrich, Germany). Diprivan ${ }^{\circledR}$ was supplied by Astra Zeneca Macclesfield, UK. Double distilled water was used for all preparations. Chemicals for high-pressure liquid chromatography (HPLC) were HPLC grade and all other chemicals were analytical grade.

\section{Methods}

Preparation propofol nanoemulsion in NEMS ${ }^{\mathrm{TM}}$

The preparation of nanoemulsion was adopted from Prasetyo, et al. [19]. The nanoemulsion was prepared using the mixture of POO and MCT oil (1:1). High-pressure homogenizer was chosen as the method 
to produce the nanoemulsion. POO, MCT oil, propofol (1\% and $2 \%)$ and all ingredients that dissolved in oil were mixed in oil phase at 70 ${ }^{\circ} \mathrm{C}$. The water-soluble ingredients were mixed in the aqueous phase using the same temperature. Then, the mixture was homogenized by using homogenizer at 10,000 rpm for $6 \mathrm{~min}$. The final nanoemulsion was prepared by using high-pressure homogenization methods at 600 bar and 8 cycles. All of preparation processes were done aseptically in a clean room to ensure the sterility of nanoemulsion product.

\section{Determination of free propofol concentration in aqueous phase}

The determination method was adopted from Schicher et al. [20]. Propofol nanoemulsion $(8.9 \mathrm{ml})$ in optiseal tube (Beackman coulter, USA) was centrifuged at $30,000 \mathrm{rpm}$ and $4{ }^{\circ} \mathrm{C}$ for $5 \mathrm{~h}$. The aliquot (10 $\mu \mathrm{l})$ was taken using syringes and injected to the HPLC system to determine the concentration of free propofol contents. The HPLC analysis was performed with Waters system. The HPLC system was composed of a controller (Waters 600), a degasser AF, an autosampler (Waters 2707), and a photodiode array detector (Waters 2998). The separation was achieved with a reversed phase C18 $(25 \mathrm{~cm} \times 4.6 \mathrm{~mm} ; 5 \mu \mathrm{m}$ particles $)$ column. The mobile phase consisted of methanol and deionised water. It was sonicated for 15 min and then filtered through a $0.45 \mu \mathrm{m}$ membrane filter paper. The wavelength use was $276 \mathrm{~nm}$. Chromatography analysis was performed at ambient temperature $\left(20 \pm 2^{\circ} \mathrm{C}\right)$.

\section{Animals}

Male Sprague-Dawley rats weighing $300 \pm 20 \mathrm{~g}$ were obtained from Animal House of University Kebangsaan Malaysia. All rats were acclimatized to their environment for $1 \mathrm{w}$ before the test. All rats were kept in the stainless steel cage and had free access to standard pellet and water ad libitum. The rats were exposed to 12 -h periods of light and darkness. The temperature and humidity of the room were maintained at $22 \pm 2{ }^{\circ} \mathrm{C}$ and $65 \%$, respectively. Animal protocols were approved by the Animal ethic Committee of Universiti Kebangsaan Malaysia (FF/2010/Fuad/17 March/298 March 2010April 2011). The rats were not provided to food $12 \mathrm{~h}$ before tests were conducted, but had free access to water.

\section{Rat paw lick test}

Twenty four male Sprague Dawley rats were grouped in 4 groups (6 rats for each group). Each group had been given a different injection. The injections were normal saline as a negative control, P1\%, P2\% and Diprivan ${ }^{\circledR} 1 \%$ as the positive control, respectively. Injection $(100 \mu \mathrm{l})$ was given to each rat into the footpad of their hind paws. Then, the number of licking and the total time of the paws being licked was monitored over a period of $15 \mathrm{~min}$. The method was adapted from Lu et al. [21].

\section{Sleep recovery test}

Eighteen rats were divided to 3 groups and 6 rast for each group (group 1 for P1\%, group 2 for $\mathrm{P} 2 \%$ and group C for Diprivan ${ }^{\circledR}$ ). The test was conducted by giving an intravenous bolus injection of propofol nanoemulsion for $10 \mathrm{mg} / \mathrm{kg}$ body weight of rats on lateral tail vein. Each rat was observed from the beginning after injection. The time when the rats first moved after injection and when the rats become normal (full recovery) were assayed. The methods were adapted from Ravenelle et al. [22].

\section{Erythrocyte haemolysis test}

The test was performed as reported in the literature [23]. The rat's blood was collected into a test tube containing heparin and centrifuged at $2000 \mathrm{~g}$ for $5 \mathrm{~min}$. Washed 3 times with 4 volume normal saline. $2 \%$ propofol nanoemulsion $(2.5 \mathrm{ml})$ was mixed erythrocytes suspension $(0.1 \mathrm{ml})$ and incubated at $37^{\circ} \mathrm{C}$ for 1 hour in a water bath. Then, the sample was centrifuged at $2000 \mathrm{~g}$ for 5 min. The absorbance from the supernatant was determined by using spectrophotometer UV in wavelength $415 \mathrm{~nm}$ to determine \% of haemolysis. The percentage of haemolysis was determined by using this equation [24]:

$$
\% \mathrm{H}=\frac{(\text { AbsTest-Abscontrol })}{(\text { Abs 100-Abscontrol })} \times 100 \%
$$

Where: Abs test= Absorbance of samples

Abs control $=$ Absorbance of the negative control (normal saline)

Abs $100=$ Absorbance of positive control (distilled water

\section{Statistical analysis}

All the data were analysed using Statistically Package for Social Sciences (SPSS) version 16.0. Data were expressed as means \pm SD Data were performed using analysis of variance (ANOVA) test to evaluate the differences between the groups. All experiments were done in triplicate. The differences were considered to be significant at level of ${ }^{*} \mathrm{P} \leq 0.05$.

\section{RESULTS AND DISCUSSION}

Nanoemulsion are one of the dosage form that develop not only for oral route [25, 26], topical usage [27] but also populer for parenteral usage like propofol nanoemulsion. Propofol is one of the anesthetic drug that common usage in the hospital but the pain problem make this drug become not comfortable to use. Free propofol in aqueous phase from the palm oil nanoemulsion was separated from oil phase by using ultracentrifugation methods and measured using HPLC. The chromatograph of propofol in NEMS ${ }^{\mathrm{TM}}$ from HPLC result shown in fig. 1 and the results of free propofol content showed in fig. 2 . The free propofol concentration of $\mathrm{P} 1 \%$ and $\mathrm{P} 2 \%$ were $6.20 \pm 0.03 \mu \mathrm{g} / \mathrm{ml}$, $10.55 \pm 0.23 \mu \mathrm{g} / \mathrm{ml}$, respectively. The results were smaller than in Diprivan ${ }^{\circledR} 1 \%(15.02 \pm 0.33 \mu \mathrm{g} / \mathrm{ml})$. Statistical test showed that there was a significant difference between P1\% compared with Diprivan ${ }^{\circledR}$ $1 \%\left({ }^{*} \mathrm{P}<0.05\right)$ whereas $\mathrm{P} 2 \%$ showed no significant differences although it showed the smaller free propofol concentration. The results showed that propofol in $\mathrm{NEMS}^{\mathrm{TM}}$ reduced the intensity of pain because it had less free propofol content compared than Diprivan ${ }^{\circledR} 1 \%$.

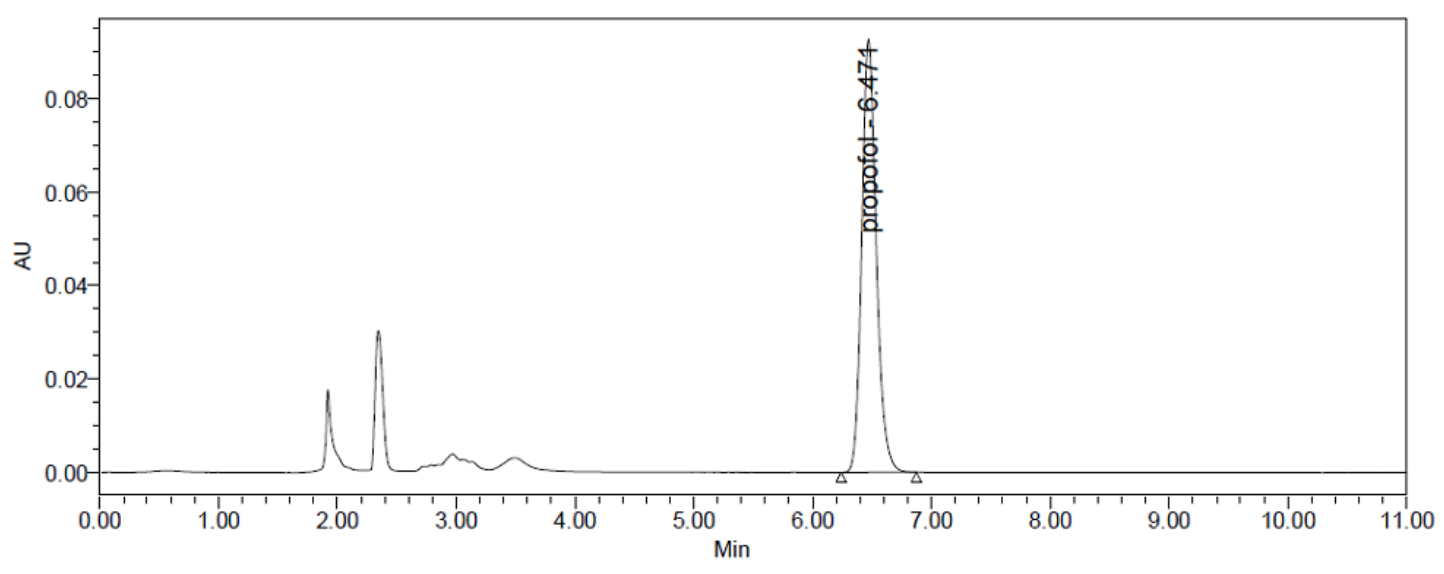

Fig. 1: Chromatograph of propofol in NEMS ${ }^{\mathrm{TM}}$ 


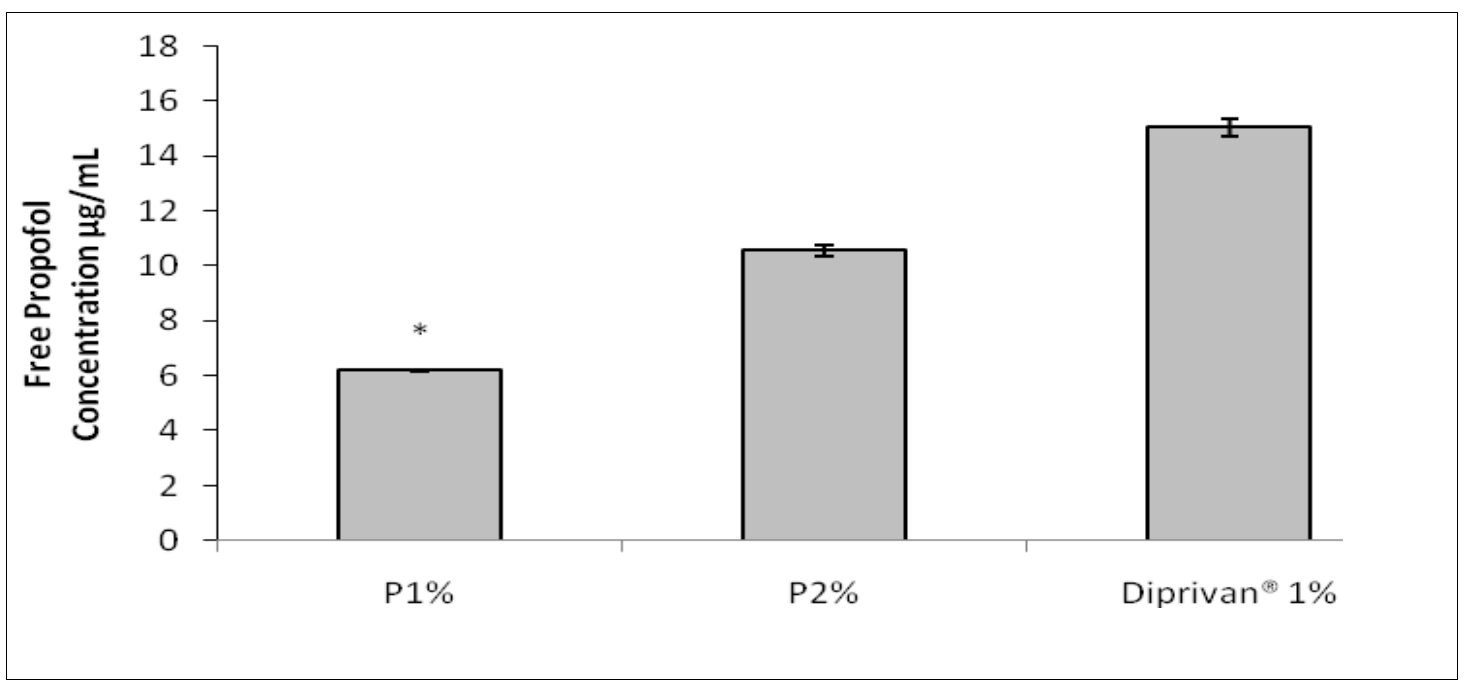

Fig. 2: Free propofol content in P1\% and P2\% compared with Diprivan ${ }^{\circledR} 1 \%(m e a n \pm S D ; n=6)$

The clear mechanism how propofol induced pain on injection site is still not well understood. One of the possibility is because propofol is one of phenol that can irritate the skin, mucous membrane, and venous intima [28]. The other opinion stated that the activation of the kallikrein-kinin system will induce in pain [29]. Many studies showed that, the intensity of pain related to increase the free propofol concentration in aqueous phase. This is one of the reason why MCT/ICT formulation become one of the solution to decrease this problem [30,31].

Propofol nanoemulsion in NEMS ${ }^{\mathrm{TM}}$ is one of the MCT/ICT formulation for propofol that using palm oil as a basic oil to develop the formulation. From this formulation, hopefully it will reduce the free propofol concentration and it can be used as alternative for propofol carrier in nanoemulsion preparation. Determination of free propofol concentration were performed to assay the free propofol concentration. In this formulation, the concentration of free propofol in NEMS ${ }^{\mathrm{TM}}$ is smaller than in Diprivan ${ }^{\circledR}$ from the rat paw lick test, the intensity of pain from propofol in NEMS $^{\mathrm{TM}}$ is lower than Diprivan ${ }^{\circledR}$.
The rat paw lick test was performed to observe if there were a relation between content of free propofol concentration and pain in the animal test. This test was done as in vivo test to measure the intensity of pain of propofol nanoemulsion at injection site. The principle of this test was if the intensity of the nanoemulsion increase, so the number of rats licking their paw and the number of time licking also increased [32-34]. As can be seen from table 1, the licking happened in all of the formulations. The results showed that P1\% and P2\% had less licking compared to Diprivan ${ }^{\circledR} 1 \%$. Statistical test showed that there was a significant difference between $\mathrm{P} 1 \%$ and Diprivan ${ }^{\circledR} 1 \%\left({ }^{*} \mathrm{P}<0.05\right)$. whereas P2\% showed no significant differences. This results showed an appropriateness with free propofol concentration in aqueus phase in case where free propofol concentration of propofol in $\mathrm{NEMS}^{\mathrm{TM}}$ showed smaller that in Diprivan ${ }^{\circledR}$ therefore it can reduce the pain. In P2\%, the free propofol concentration were still quite high because not all of propofol dissolved in oil phase of the nanoemulsion, but it was smaller than Diprivan ${ }^{\circledR}$ nanoemulsion.

Table 1: Results of rat paw-lick test

\begin{tabular}{lll}
\hline Formulation & The number of licking (time) & The number of time of licking (min) \\
\hline Normal saline & $2.5 \pm 0.7$ & $19.5 \pm 6.4$ \\
P1\% & $8.3 \pm 1.2^{*}$ & $39.5 \pm 6.7^{*}$ \\
P2\% & $9.8 \pm 2.0$ & $46.6 \pm 12.1$ \\
Diprivan $^{\circledR} 1 \%$ & $11.2 \pm 1.9$ & $59.5 \pm 7.3$ \\
\hline
\end{tabular}

$($ mean $\pm S D ; n=6) * P 1 \%(P<0.05)$ when evaluated with Diprivan ${ }^{\circledR} 1 \%$.

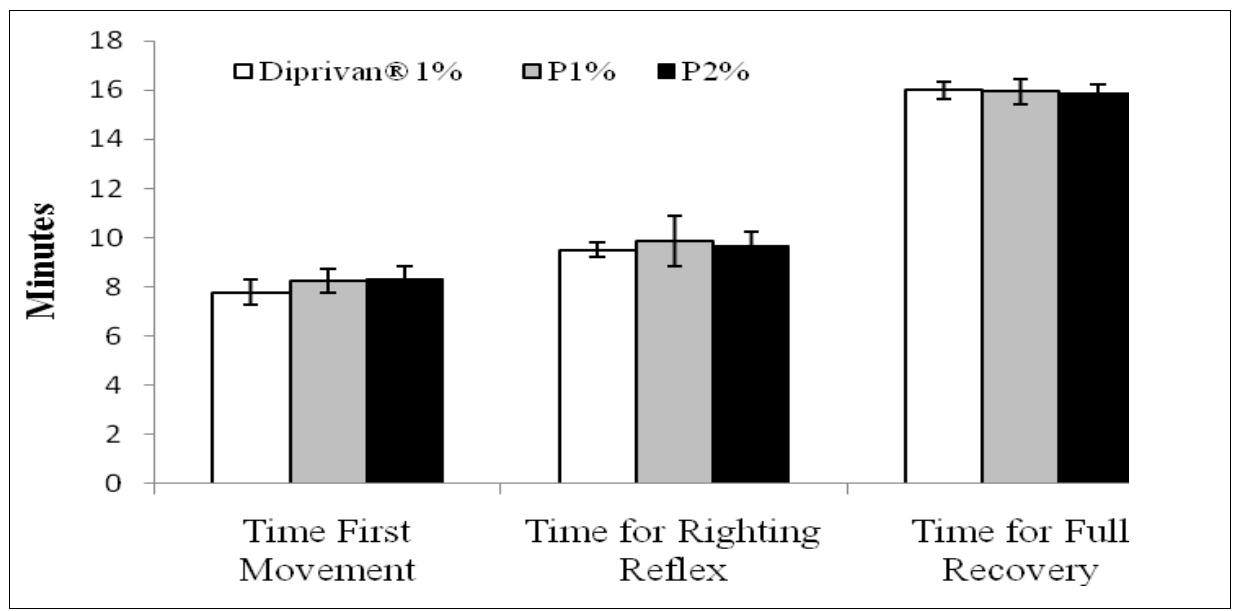

Fig. 3: Profile of sleep test recovery of propofol in NEMS ${ }^{m}$ compared with diprivan ${ }^{\circledR} 1 \%($ mean $\pm S D ; n=6)$ 
It was observed from fig. 3., that there were no significant differences $(p>0.05)$ between P1\%, P2\% and Diprivan ${ }^{\circledR} 1 \%$ as standard. All rats started to sleep not more than $1 \mathrm{~min}$ after injection. From this test, the effect of propofol in NEMS ${ }^{\mathrm{TM}}$ almost similar with Diprivan ${ }^{\circledR} 1 \%$ in all parameters test. The rats started to open their eyes after $8 \mathrm{~min}$, try to wake up after 9 min and back in normal condition after $15 \mathrm{~min}$. NEMS ${ }^{\mathrm{TM}}$ showed a very good result in pharmacological test. This carrier had similar effect with Diprivan ${ }^{\circledR}$ It meant that the drug had a good release profile after being injected to the rats. There were no significant differences $(p>0.05)$ between all of the formulations.

\section{Haemolysis test}

The purpose of this test was to ensure that this formula would give damage or not to the blood [35]. The result showed that distilled water caused 100\% hemolysis in blood. Whereas P1\%, P2\% and Diprivan ${ }^{\circledR} 1 \%$ were cause a little bit hemolysis in blood, but it was still fulfilled the safety requirement (fig. 4). Parenteral administration of the drug still safety to use if the \% haemolysis of the formulation below than $20 \%$ [36]. The reason of this phenomena happen is due to the composition of the emulsion like a phospholipid in emulsion would cause interaction with red blood cell [37].

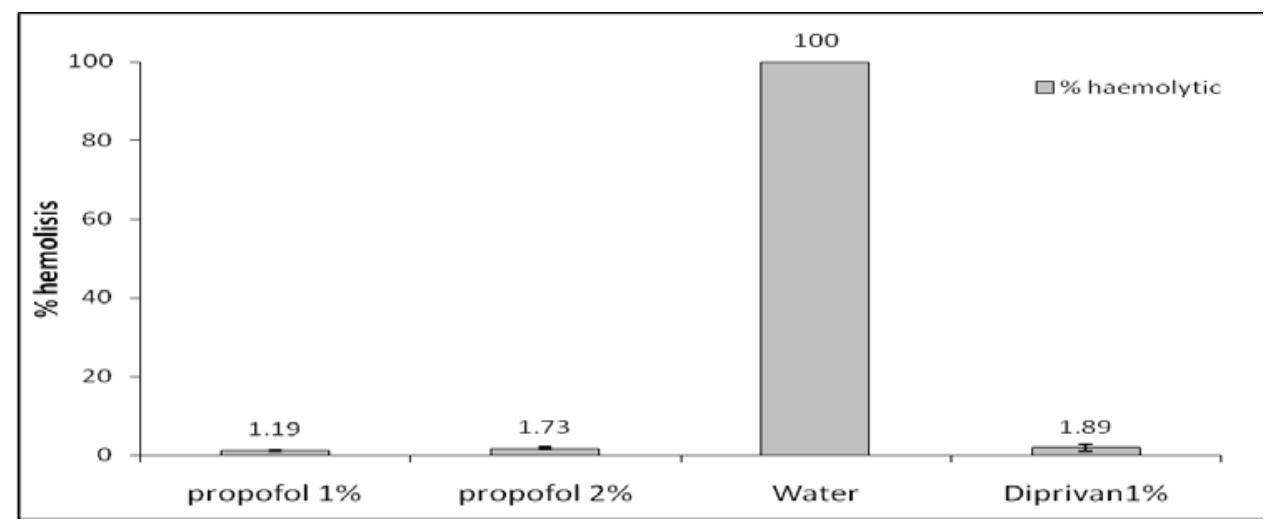

Fig. 4. The amount of red blood cell remaining after hemolysis test (mean $\pm S D, n=6$ )

\section{CONCLUSION}

In summary, palm oil in $\mathrm{NEMS}^{\mathrm{TM}}$ has proven its potential to produce a propofol nanoemulsion and from the results indicated that palm oil in NEMS $^{\text {TM }}$ is promising carrier system for propofol and successfully reduced the free propofol contents and the intensity of pain on injection site in rats.

\section{ACKNOWLEDGMENT}

This project was supported by a grant from The Malaysian Technology Development Corporation under project UKM-MTDC-BF 0003-2008. The authors are thankful to Dr Srijit Das (The National University of Malaysia) and Miss Lia Laila (Universitas Sumatera Utara) who helped for correcting the manuscript.

\section{AUTHORS CONTRIBUTIONS}

All Authors have contributed equally

\section{CONFLICT OF INTERESTS}

\section{Declared none}

\section{REFERENCES}

1. Egan TD. Exploring the frontiers of propofol formulation strategy: is there life beyond the Milky Way? $\mathrm{Br} \mathrm{J}$ Anaesth 2010;104:533-5.

2. Baker MT, Mohamed N. Propofol, the challenges of formulation. Anesthesiology 2005;103:860-76.

3. Prakash KD. Pain on injection of lipid-free propofol and propofol nanoemulsion containing medium-chain triglyceride: a comparative study. Anesth Analg 2005;101:1060-2.

4. Lee SK. Pain in injection with propofol. Korean J Anesthesiol 2010;59:297-8.

5. Saadawy I, Erturgrul E, Abdulaziz B. Painless injection of propofol: pretreatment with. M E J Anesth 2007;19:631-44.

6. Shimizu T, S Inomata, S Kihara, H Toyooka, J Brimacombe. Rapid injection reduces pain on injection with propofol. Eur J Anaesth 2005;22:394-6.

7. Banjong K, Siriwan D, Sujarit K, Malin T. Comparison on pain on injection of a small particle size-lipid nanoemulsion of propofol and standard propofol with or without lidocaine. J Med Assoc Thai 2005;88:1401-5.
8. Cheong MA, Kyo SK, Won JC. Ephedrine reduces the pain from propofol injection. Anesth Analg 2002;95:1293-6.

9. Hüseyin S, Omer Y, Ali S, Mehmet M, Sezai O, Güner D. Effect of saline dilution on propofol injection pain: comparison with lidocaine. Turkiye Klinikleri J Med Sci 2009;29:150-4.

10. Khouadja H, Arnous H, Tarmiz K, Beletaifa D, Brahim A, Brahem $\mathrm{B}$, et al. Pain on injection of propofol: efficacy of paracetamol and lidocaine. Open J Anesth 2014;4:81-7.

11. Başak N, Yakup Aksoy, Ayhan Kaydu, Omer Fatih Sahin. Lornoxicam use to reduce the pain associated with propofol injection. Libyan J Med 2017;12:1313093.

12. Nicholas CH, Sun, Andrew YC, Wong, Michael GI. A comparison of pain on intravenous injection between two preparations of propofol. Anesth Analg 2005;101:675-8.

13. Hiroshi O, Shinju 0, Hiroshi I. Mechanism of injection pain with long and long-medium chain triglyceride emulsive propofol. Can J Anesth 2005;52:595-9.

14. Yamakage M, Sohshi I, Jun-Ichi S, Akiyoshi N. Changes in concentrations of free propofol by modification of the solution. Anesth Analg 2005;101:385-8.

15. Sundarathiti P, Nuanjai B, Therawat C, Porpimon J, Wanadee R. A comparison of propofol LCT with propofol-LCT/MCT on pain of injection. J Med Assoc Thai 2007;90:2683-8.

16. Mukherjee S, Analava M. Health effects of palm oil. J Hum Ecol 2009;26:197-203.

17. Khosla P. Palm oil: a nutritional overview. AgroFOOD industry hi-tech Anno; 2006. p. 17.

18. Sundram K. Palm oil: chemistry and nutrition updates. Malaysian Palm Oil Board (MPOB), Kuala Lumpur; 2003.

19. Prasetyo BE, Norazrina A, Shamsuddin AF. Preparation and physical stability evaluation of palm oil-based nanoemulsion as a drug delivery system for propofol. JSKM 2018:16:5-1.

20. Schicher M, Margit $\mathrm{P}$, Albin H, Ruth $\mathrm{P}$, Andreas Z. In vitro release of propofol and binding capacity with regard to plasma constituents. Eur J Pharm Biopharm 2008;70:882-8.

21. Lu Y, Wang YJ, Tang Q. Formulation and thermal sterile stability of a less painful intravenous clarithromycin nanoemulsion containing vitamin E. Int J Pharm 2008;346:4756.

22. Ravenelle F, Sandra G, Dorothee L. Novel lipid and preservative-free propofol formulation: properties and pharmacodynamics. Pharm Res 2008;25:312-9. 
23. Wang JJ, KC Sung, Oliver Y, Chih HY, Jia YF. Submicron lipid emulsion as a drug delivery system for nalbuphine and its prodrugs. J Controlled Release 2006;115:140-9.

24. Date AA, Nagarsenker MS. Design and evaluation of microemulsions for improved parenteral delivery of propofol. AAPS PharmSciTech 2008;9:138-45.

25. Almajidi Y, Mahdi Z, Maraie N. Preparation and in vitro evaluation of montelukast sodium oral nanoemulsion. Int Appl Pharm 2018;10:49-53.

26. Franklyne JS, Abinaya N, Andrew E, Nisha T, Amitava. Preparation and characterization of edible oil nanoemulsions for enhanced stability and oral delivery of curcumin. Int J Appl Pharm 2018;10:139-46.

27. Suminar MM, Mahdi J. Physical stability and antioxidant activity assay of nanoemulsion gel formulation containing tocotrienol. Int J Appl Pharm 2017;9 Suppl 1:140-3.

28. Ambesh SP, Prakash KD, Prabhat KS. Ondansetron pretreatment to alleviate pain on propofol injection: a randomized, controlled, double-blinded study. Anesth Analg 1999;89:197-9.

29. Scott RPF, Saunders DA, Norman J. Propofol: clinical strategies for preventing the pain of injection. Anaesthesia 1988;43:492-4.

30. Ohmizo H, Obara S, Iwama H. Mechanism of injection pain with long and long-medium chain triglyceride emulsive propofol. Can J Anaesth 2005;52:595-9.
31. Babl J, Doenicke A, Monch V. New formulation of propofol in an LCT/MCT nanoemulsion. Approach to reduce pain on injection. Eur Hosp Pharm 1995;1:15-21.

32. Lovell MW, Johnson HW, Hui HW, Gupta PK, Hsu CC. Less painful nanoemulsion formulations for intravenous administration of clarithromycin. Int J Pharm 1994;109:45-57.

33. Celozzi E, Lotti VJ, Stapley EO, Miller AK. An animal model for assessing pain-on-injection of antibiotics. J Pharmacol Meth 1980;4:285-9.

34. Chellman G, George FF, Lance OL, Tim EM. Rat paw-lick/muscle irritation model for evaluating parenteral formulations for pain-on-injection and muscle damage. Toxicol Sci 1990;15:697709.

35. Jumaa M, Muller BW. In vitro investigation of the effect of various isotonic substances in parenteral emulsions on human erythrocytes. Eur J Pharm Sci 1999;9:207-12.

36. Krzyzaniak JF, Raymond DM, Yalkowsky SH. Lysis of human red blood cells 2: effect of contact time on cosolvent induced hemolysis. Int J Pharm 1997;152:193-200.

37. Ishii F, Nagasaka Y. Interaction between erythrocytes and free phospholipids as an emulsifying agent in fat emulsions or drug carrier emulsions for intravenous injections. Coll Surf B: Biointerfaces 2004;37:43-7. 